\title{
Online Collaboration Via Email: Analyzing Students Knowledge Construction In The ESL Classroom
}

\begin{abstract}
This study explores students' knowledge construction in an online collaboration via email discussion. The primary focus of this study centres on how participants communicate via email in a collaborative learning environment incorporating process writing approach and pair work activity. The data for this study embraces the email messages and writing assignments. Findings are that participants' knowledge construction process transpired from an interactive process focusing on three main categories: questions, clarification and support. The findings will contribute to the development and testing of the efficacy and flexibility of process approaches to ESL writing instruction through e-mail. The study offers positive views for further study to be explored in order to attain a better understanding of how learners interact and construct knowledge in a collaborative learning environment via email discussions.
\end{abstract}

Keyword: Collaborative learning, email discussion, knowledge construction 